\title{
Templated crystallization of octadecanol on patterned nanoassemblies
}

\author{
Adam J. Dickie, Florence Quist, M.A. Whitehead and Ashok K. Kakkar* \\ Department of Chemistry, McGill University, 801 Sherbrooke St. West \\ Montreal, H3A 2K6 Canada
}

\section{Supplementary Information:}

\section{Crystal Growth}

Glass, quartz, or $\mathrm{Si}(100) / \mathrm{SiO}_{2}$ substrates, measuring approx. $5.1 \times 1.3 \mathrm{~cm}$, were first soaked in $1: 1 \mathrm{MeOH}: \mathrm{HCl}$ for 30 minutes. Following extensive rinsing with distilled water, the slides were treated with conc. $\mathrm{H}_{2} \mathrm{SO}_{4}$ for 2 hours at $60^{\circ} \mathrm{C}$. The substrates were again rinsed, then soaked in distilled water for about $30 \mathrm{~min}$. The slides were dried under a stream of $\mathrm{N}_{2}$, at $100^{\circ} \mathrm{C}$ for 15 minutes, and finally under vacuum for an additional 15 minutes.

Cleaned substrates were immersed into freshly prepared $2.5 \times 10^{-3} \mathrm{M}$ solutions of $\left(\mathrm{NMe}_{2}\right)_{3} \mathrm{Si}-\mathrm{O}-\mathrm{X}-\mathrm{C} \equiv \mathrm{C}-\mathrm{Sn}(\mathrm{NEt})_{3}$ in toluene, under a nitrogen atmosphere. After 5 minute deposition time, the substrates were removed from the solution and transferred into a solution of phenylacetylene $(0.22 \mathrm{~mL}, 2.0 \mathrm{mmol})$ in toluene, and left to stand for 16 hours at room temperature 1-Octadecanol $(0.54 \mathrm{~g}, 2.0 \mathrm{mmol})$ was then added to the reaction mixture, and left to stand for an additional 24 hours. Slides were removed from solution, and left to dry standing vertically in a vial under air. After 24 hours, crystals with various morphologies were found to have grown on the substrate surfaces. ${ }^{1} \mathrm{H}-\mathrm{NMR}\left(400 \mathrm{MHz}, \mathrm{C}_{6} \mathrm{D}_{6}\right): \delta 3.31\left(\mathrm{~m}, \mathrm{CH}_{2}\right), 1.32\left(\mathrm{~m}, \mathrm{CH}_{2}\right)$, $0.91\left(\mathrm{t}, \mathrm{CH}_{3}\right) .{ }^{13} \mathrm{C}-\mathrm{NMR}\left(400 \mathrm{MHz}, \mathrm{C}_{6} \mathrm{D}_{6}\right): \delta 62.50\left(-\mathrm{O}-\mathrm{CH}_{2}-\left(\mathrm{CH}_{2}\right)_{16} \mathrm{CH}_{3}\right), 33.75\left(-\mathrm{OCH}_{2}-\mathrm{CH}_{2}-\left(\mathrm{CH}_{2}\right)_{16} \mathrm{CH}_{3}\right), 30.26,25.60(-\mathrm{O}-$ $\left.\left(\mathrm{CH}_{2}\right)_{2}-\left(\mathrm{CH}_{2}\right)_{14}-\left(\mathrm{CH}_{2}\right)-\mathrm{CH}_{3}\right), 23.46\left(-\mathrm{O}-\left(\mathrm{CH}_{2}\right)_{16}-\mathrm{CH}_{2}-\mathrm{CH}_{3}\right), 18.31\left(-\mathrm{O}-\left(\mathrm{CH}_{2}\right)_{17}-\mathrm{CH}_{3}\right)$.
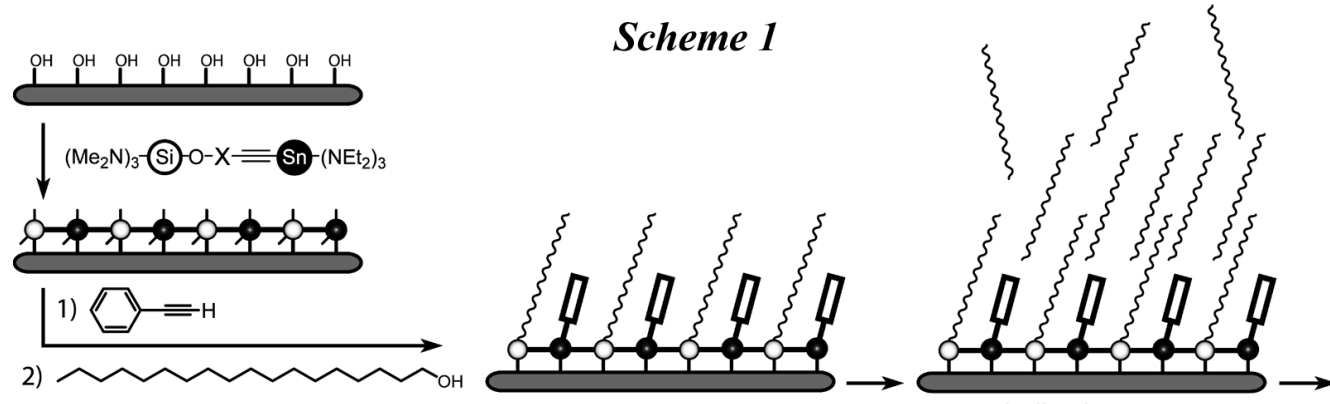

bulk adsorption

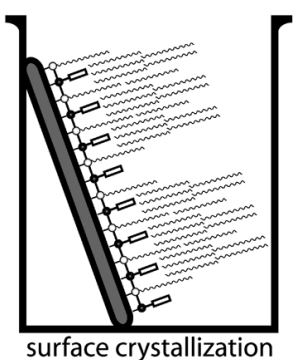

\section{X-ray diffraction (XRD)}

X-Ray diffraction data were collected using a Siemens D-5000 diffractometer, consisting of a step scanner equipped with a $1.2 \mathrm{~kW}$ cobalt tube $(\lambda=1.78897 \AA)$ coupled to a silicon detector. The diffraction patterns were acquired for $2 \theta$ values ranging from 2 to 90 degrees for the surface-adsorbed crystallites. Crystals were analyzed on the substrate and were not scrapped off from the surface or powdered. The acquisition of XRD data was done in the reflection mode. The X-ray beam was fixed while the sample holder and the detector moved to scan the surface crystals. In the beginning, the beam was at a tangent to the surface, then moved to be at normal to the surface, and finally back to the position which was at a tangent to the surface. After 100 degree, peaks repeated themselves and the analysis was done in the diffraction mode. Data Refinement: XFIT (Cheary, R.W.; Coelho, A.A., Engineering and Physical Sciences Research Council, Daresbury Laboratory, Warrington, England, 1996) and CRYSFIRE (Shirley, R., The CRYSFIRE system for Automatic Powder Indexing: User's Manual, The Lattice Press, 41 Guildford Park Avenue, Guidlford, England 2000) software systems were used for refinement and indexing of peak data. As discussed in the manuscript, multilayered linear crystals showed a higher degree of structural order than the dendritic crystals. High crystallinity is achieved through multilayer stacking of octadecanol, and a decrease in thickness reduces the crystalline order and produces dendritic crystals. Although the atomic positions were not assigned, the calculated unit cell correlated well with the length of an octadecanol chain $(22.4 \AA$ ) , and the $40 \AA$ cell length suggested stacked alkyl chain bilayers as the crystalline unit.

\section{Fourier transform infrared (FTIR) spectroscopy}

FT-IR spectroscopic measurements on surface crystalline materials were performed using a $15 \times$ optical/IR microscope with a liquid nitrogen cooled mercury-cadmium-telluride detector, attached to the Bruker IFS-48 spectrometer. Cleaned, unfunctionalized $\mathrm{Si}(100) / \mathrm{SiO}_{2}$ wafers were used for background corrections. The FT-IR spectrum of the crystals typically showed peaks at $2921 \mathrm{~cm}^{-1} v_{\text {as }}\left(\mathrm{CH}_{2}\right), 2852 \mathrm{~cm}^{-1} \mathrm{v}_{\mathrm{s}}\left(\mathrm{CH}_{2}\right)$; those for commercial octadecanol are, in the powder form $\left(\mathrm{v}_{\text {as }}\left(\mathrm{CH}_{2}\right) 2937 \mathrm{~cm}^{-1}\right.$, 
$\left.v_{\mathrm{s}}\left(\mathrm{CH}_{2}\right) 2861 \mathrm{~cm}^{-1}\right)$ or solid chip form $\left(\mathrm{v}_{\mathrm{as}}\left(\mathrm{CH}_{2}\right) 2939 \mathrm{~cm}^{-1}, \mathrm{v}_{\mathrm{s}}\left(\mathrm{CH}_{2}\right) 2864 \mathrm{~cm}^{-1}\right)$. A comparison of the data clearly shows that the surface crystalline assemblies are highly ordered and densely packed.

\section{Photography}

Photographic characterization of surface crystals was performed at three different size scales. At $5 \mathrm{~cm}$ scale, a standard $50 \mathrm{~mm}$ camera lens, fitted with a +6 close-up filter, was used. For $5 \mathrm{~mm}$ scale photos, a camera fitted to an $8 \times$ microscope was used to image the surfaces. At the $500 \mu \mathrm{m}$ scale, images were obtained from a CCD video display of the $15 \times$ optical/IR microscope. Only white light was used as the illumination source; no colour enhancements or polarizations were performed on the images. Crystals obtained using $\left(\mathrm{NMe}_{2}\right)_{3} \mathrm{Si}-\mathrm{O}-\left(\mathrm{CH}_{2}\right)_{2}-\mathrm{C} \equiv \mathrm{C}-\mathrm{Sn}\left(\mathrm{NEt}_{2}\right)_{3}$ are shown in the graphical abstract. Figure below shows crystals obtained using surface activation $\left(\mathrm{NMe}_{2}\right)_{3} \mathrm{Si}-\mathrm{O}-\mathrm{C}_{6} \mathrm{H}_{4}-\mathrm{C} \equiv \mathrm{C}-\mathrm{Sn}\left(\mathrm{NEt}_{2}\right)_{3}$.
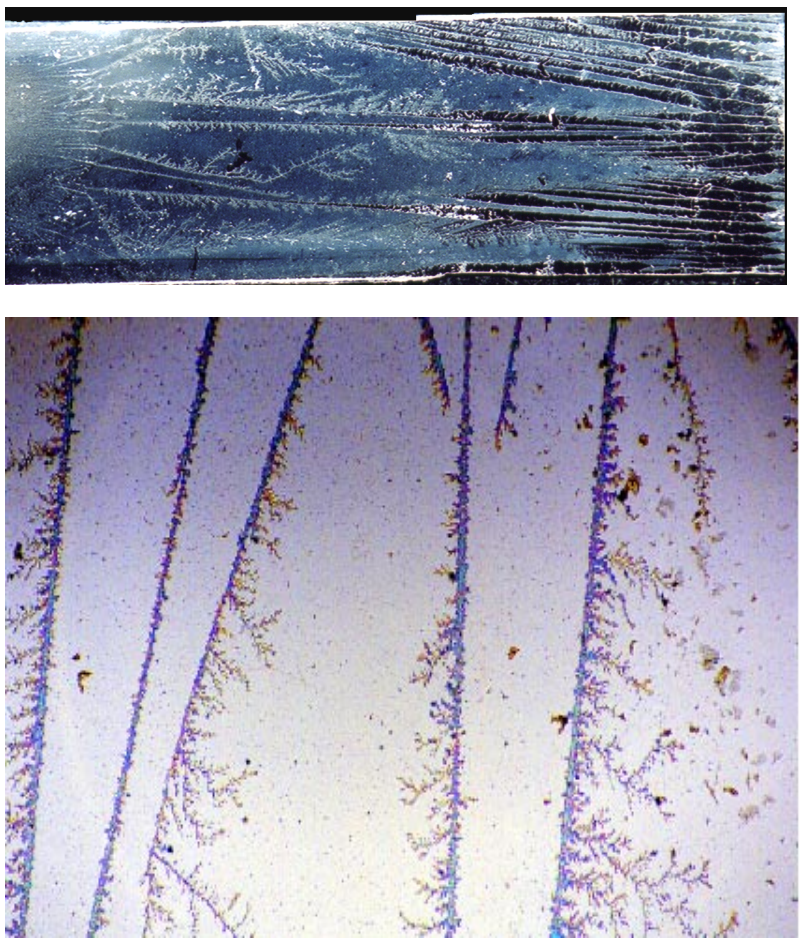

\section{Atomic force microscopy (AFM)}

AFM experiments were performed with an Autoprobe (CP scanning probe) microscope from Park Scientific Instruments. Topographic images were obtained in the tapping mode, using a $2 \mu \mathrm{m}$ thick non-contact mode silicon cantilever, operating at approximately $450 \mathrm{kHz}$. AFM images of branched surface crystals (Fig. 1) obtained using the surface activation unit $\left(\mathrm{NMe}_{2}\right)_{3} \mathrm{Si}_{-}$ $\mathrm{O}-\left(\mathrm{CH}_{2}\right)_{3}-\mathrm{C} \equiv \mathrm{C}-\mathrm{Sn}\left(\mathrm{NEt}_{2}\right)_{3}$ (1a) 2-D, $60 \mu \mathrm{m} \times 60 \mu \mathrm{m}$ scan of the crystals and the underlying thin film interface, (1b) 3-D representation of the data, are shown below. Scale indicates the relative height of imaged materials.

Fig. 1

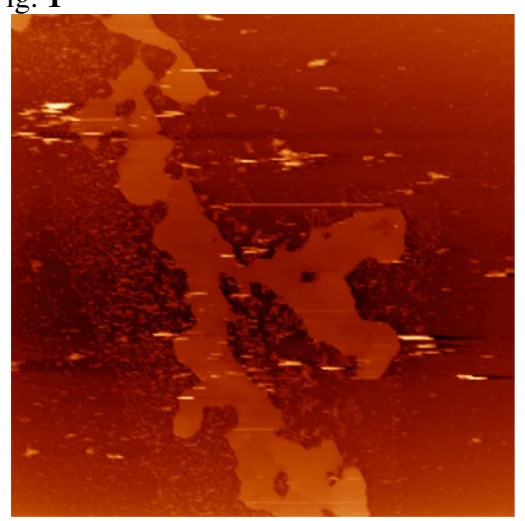

(b)

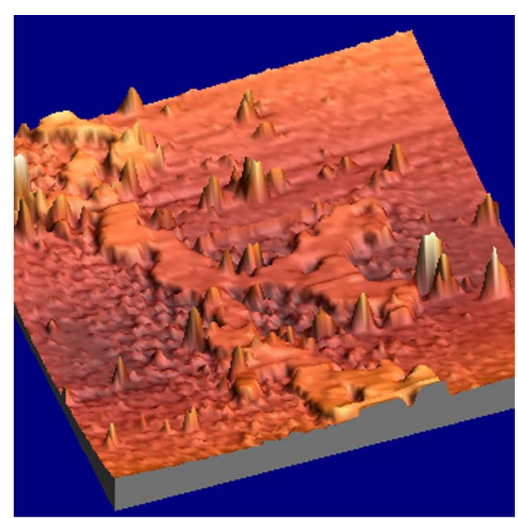

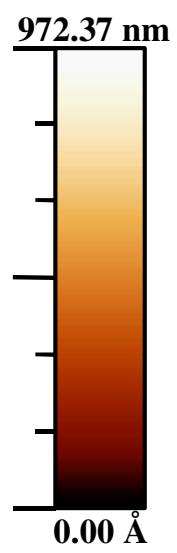


The topographic AFM images of the crystals with dendritic morphology are shown in Fig. 1. The dendritic shape is well defined by the microscope topography with a height difference of approx. $50 \mathrm{~nm}$ between the substrate and the top of the dendritic crystal. There was island growth observed around the solid crystalline material.

AFM images of the linear crystals (Fig. 2) obtained using the surface activation unit $\left(\mathrm{NMe}_{2}\right)_{3} \mathrm{Si}-\mathrm{O}-\left(\mathrm{CH}_{2}\right)_{3}-\mathrm{C} \equiv \mathrm{C}-$ $\mathrm{Sn}\left(\mathrm{NEt}_{2}\right)_{3}$ (2a) 2-D, $50 \mu \mathrm{m} \times 50 \mu \mathrm{m}$ scan of linear crystal edge and the underlying thin film interface, (2b) 3-D representation of the data, (2c) 2-D, $50 \mu \mathrm{m} \times 50 \mu \mathrm{m}$ scan along the top of linear crystal surface, (2d) 3-D representation of data shown in (2c), are shown below.

Fig. 2

(a)
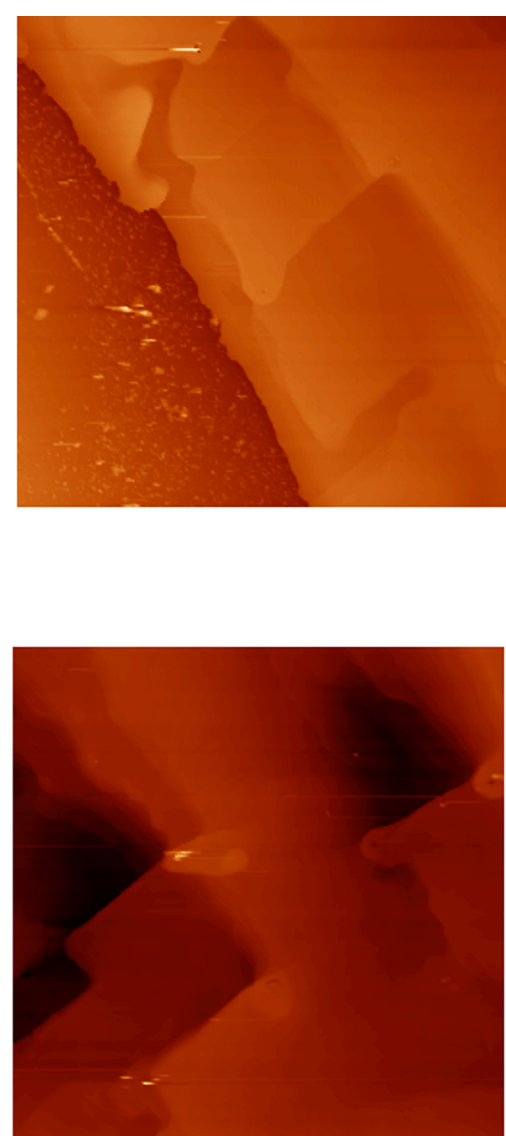

(b)
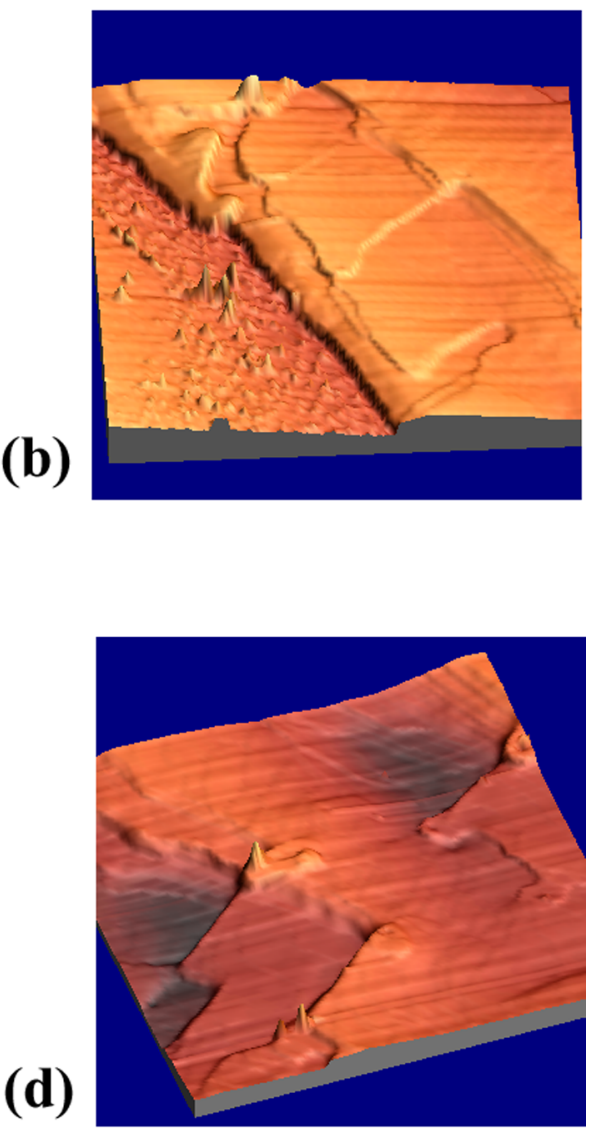

The highly crystalline, thick and layered morphology of the linear crystals is apparent in Fig. 2. Sharp, rectangular edges between crystalline layers are seen on the top faces of the linear materials. Modification of the $\mathrm{SiO}_{2}$ thin film interface is also observed, with discrete island structures seen in the vicinity of the crystal/surface edge. 
AFM image (Fig. 3) of the interface after removal of crystals obtained using $\left(\mathrm{NMe}_{2}\right)_{3} \mathrm{SiO}-\left(\mathrm{CH}_{2}\right)_{3}-\mathrm{C} \equiv \mathrm{C}-\mathrm{Sn}\left(\mathrm{NEt}_{2}\right)_{3}, 30 \mu \mathrm{m} x$ $30 \mu \mathrm{m}$ scan, vertical scale $0-50 \mathrm{~nm}$ is shown below.

Fig. 3

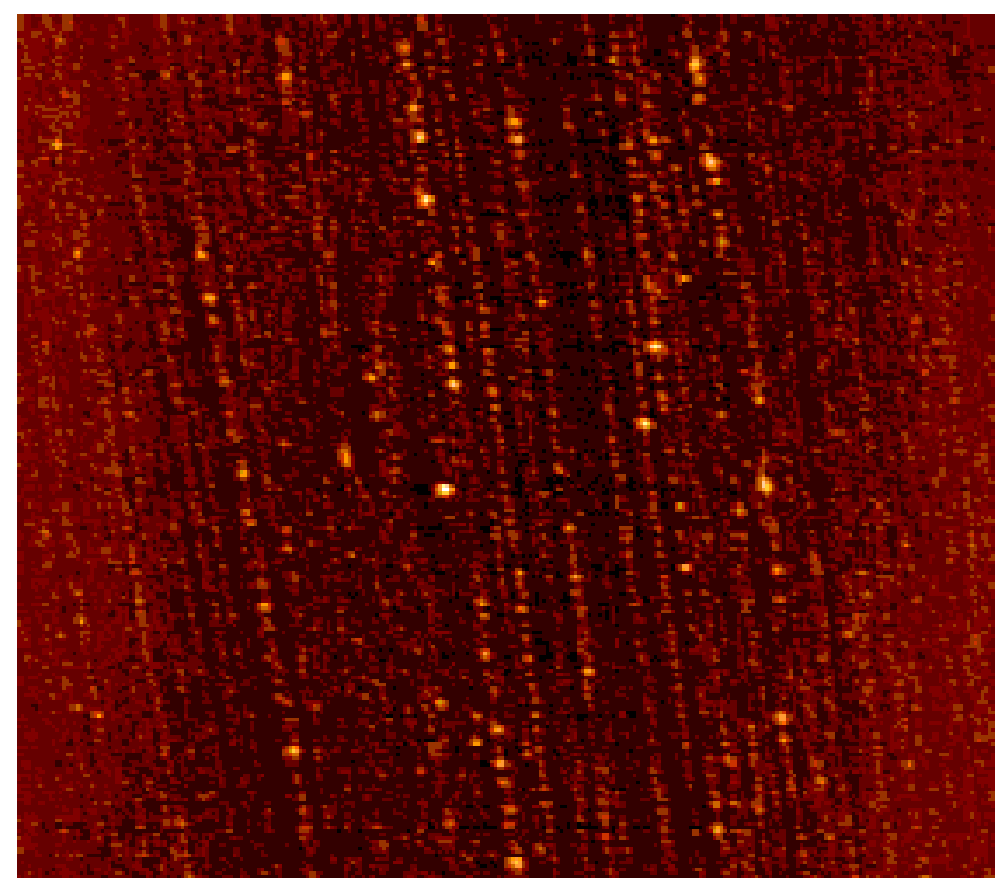

The AFM image of the interface with all surface crystals removed is shown in Fig. 3. The interfacial structure in the bicomponent thin films promotes crystalline growth. The anisotropic features on the surface likely serve as nucleation sites for crystalline growth, adsorbing free molecules out of solution into these thin film structures, as previously demonstrated for crystallization on monolayers (Aizenberg, J.; Black, A.J.; Whitesides, G.M. Nature, 1999, 398(8), 495), and alignment of liquid crystals at solid interfaces (Lee, B.; Clark, N.A. Science, 2001, 291, 2576). The bicomponent thin films lead to an open structure that promotes densely packed crystalline growth. The use of $\left(\mathrm{NMe}_{2}\right)_{3} \mathrm{Si}-\mathrm{O}-\mathrm{R}-\mathrm{C} \equiv \mathrm{C}-\mathrm{Sn}\left(\mathrm{NEt}_{2}\right)_{3}$ surface coupling agents gives us flexibility in controlling octadecanol crystalline habits by manipulating the structure of our thin film nanoassemblies.

Summary: Atomic force microscopy provided topographic information about the crystalline assemblies and the thin film interface. The linear crystals were found to be thick and layered materials with AFM profile analysis showing a $40 \mathrm{~nm}$ difference between crystal layers, and a sharp $250 \mathrm{~nm}$ height difference between the solid interface and the top of the crystal surface. Dendritic crystals showed a height difference of approx. $50 \mathrm{~nm}$ between the substrate and the top of the crystal. The interfacial island growth was observed around the crystalline materials.

\section{Ellipsometry}

A Gaertner Scientific ellipsometer, equipped with a $633 \mathrm{~nm}$ He-Ne laser, was used for thickness measurements. Measurements were averaged over 15 - 20 individual surface readings, and thickness values were calculated by measuring the surface before and after functionalization. A refractive index of 1.46 was used to calculate film thickness, a value that assumes a semi-crystalline bulk structure comparable to paraffin assemblies. Accounting for variations of this refractive index, the instrument uncertainty is $\pm 2 \AA$. Ellipsometry measurements indicated that the surface activation units lie flat on the surface, adsorbing phenylacetylene and octadecanol sequentially, with the organic molecules retaining an average, near-vertical orientation, with final average film thicknesses of $23 \AA$.

\section{X-Ray Photoelectron Spectroscopy}

The XPS spectra were obtained using a VG ESCALAB MK2 spectrometer with monochromatized MgK $\alpha$ X-Ray source to produce the photoemission of electrons from the core levels of the surface atoms. About $60 \AA$ of depth was probed for a detector $15^{\circ}$ from the surface. The power of the source was $300 \mathrm{~W}$ and a pressure of 10-9 mbar. A typical XPS data for a bicomponent monolayer using surface activation unit $\left(\mathrm{NMe}_{2}\right)_{3} \mathrm{Si}-\mathrm{O}-\left(\mathrm{CH}_{2}\right)_{2}-\mathrm{C} \equiv \mathrm{C}-\mathrm{Sn}\left(\mathrm{NEt}_{2}\right)_{3} /$ phenylacetylene/octadecanol: $\mathrm{C}(1 \mathrm{~s}) \quad 285$, O $(1 \mathrm{~s})$ 532.1, $\mathrm{Si}(2 \mathrm{p})$ 99, $\mathrm{SiO}$ 103.8, $\mathrm{Sn}(3 \mathrm{~d})$ 487.9-496.3. 